\title{
Aggressive Colorectal Cancer in an Inflammatory Bowel Disease Patient following Treatment with Vedolizumab: A Case Report
}

\author{
Catarina Nascimento ${ }^{a}$ Helena Oliveira ${ }^{b}$ Catarina Fidalgo $^{a}$ \\ Lídia Roque Ramos $^{\mathrm{a}}$ Luísa Glória ${ }^{\mathrm{a}}$ Joana Torres ${ }^{\mathrm{a}}$ \\ ${ }^{a}$ Gastroenterology Department, Beatriz Ângelo Hospital, Loures, Portugal; b Pathology Department, Beatriz Ângelo \\ Hospital, Loures, Portugal
}

Keywords

Ulcerative colitis - Melanoma - Immunosuppressive therapy · Vedolizumab · Azathioprine · Colorectal cancer

\section{Abstract}

Introduction: The increased risk of bowel cancer in patients with inflammatory bowel disease can be related with the extent, duration and severity of inflammation or with the cancer immune surveillance interference of immunosuppressive drugs used in inflammatory bowel disease treatment. Therefore, the risk-benefit ratio associated with long-term therapeutic strategies should be based on the patient's age, sex, comorbidities and disease phenotype. Case Report: We present the case of a 76-year-old man with a history of melanoma stage Clark III and steroid-dependent left-sided colitis, refractory to mesalamine and thiopurines, with a diagnosis of a multifocal colorectal adenocarcinoma shortly after clinical and endoscopic remission 1 year after starting vedolizumab. Discussion: Vedolizumab is a gut-selective monoclonal anti- $\alpha_{4} \beta_{7}$-integrin antibody that inhibits lymphocyte migration into the gastrointestinal submucosa. Its effectiveness for induction and maintenance of remission and its favorable safety profile make it an alternative in patients with chronic refractory colitis and contraindications to anti-TNF-a. However, there is the hypothesis that, by reducing the migration of activated leukocytes to the gastrointestinal tract, it may also reduce immunosurveillance, increasing the colorectal malignancy risk in the long term. More studies are necessary to address this issue.

(C) 2021 Sociedade Portuguesa de Gastrenterologia Published by S. Karger AG, Basel

\section{Cancro colo-rectal agressivo após tratamento do vedolizumab num doente com doença inflamatória do intestino: Um caso clínico}

\section{Palavras-Chave}

Colite ulcerosa $\cdot$ Melanoma $\cdot$ Terapêutica imunossupressora $\cdot$ Vedolizumab $\cdot$ Azatioprina $\cdot$ Cancro colorectal

\section{Resumo}

Introdução: O aumento do risco de neoplasias intestinais em doentes com doença inflamatória intestinal correlaciona-se com a extensão, duração e gravidade de inflama- karger@karger.com www.karger.com/pjg

Karger $\stackrel{\text { ' }}{5}$

BOPEN ACCESS (c) 2021 Sociedade Portuguesa de Gastrenterologia Published by S. Karger AG, Basel

This is an Open Access article licensed under the Creative Commons Attribution-NonCommercial-4.0 International License (CC BY-NC) (http://www.karger.com/Services/OpenAccessLicense), applicable to the online version of the article only. Usage and distribution for commercial purposes requires written permission.
Correspondence to:

Catarina Nascimento, catarina.n.nascimento@gmail.com 
ção assim como com o potencial efeito na vigilância imunitária associado aos fármacos imunossupressores utilizados no seu tratamento. Por isso, a avaliação do risco-benefício da utilização de estratégias terapêuticas a longo prazo deve basear-se no género, idade, comorbilidades e fenótipo da doença. Caso clínico: Os autores apresentam o caso de um homem de 76 anos com história pregressa de melanoma maligno estadio Clark III e colite ulcerosa esquerda cortico-dependente e refratária à terapêutica convencional, com o diagnóstico de um adenocarcinoma colo-rectal um ano após ter iniciado terapêutica com vedolizumab e ter atingido remissão clínica e endoscópica. Discussão: O vedolizumab é um anticorpo anti-integrina a4 $\beta 7$ que inibe a migração dos linfócitos para a submucosa gastrointestinal. A sua eficácia na indução e manutenção da remissão e o seu perfil de segurança tornam-no uma boa alternativa em doentes com doença refratária e contraindicações para anti-TNF-a. Contudo, ao diminuir a migração dos leucócitos para o trato gastrointestinal, poderá reduzir a imunovigilância, aumentando o risco de neoplasia colo-rectal. No entanto, este é ainda um conceito teórico, sendo necessários mais estudos que o comprovem.

(C) 2021 Sociedade Portuguesa de Gastrenterologia Publicado por S. Karger AG, Basel

\section{Introduction}

There is an increased risk of intestinal and extra-intestinal cancers in patients with inflammatory bowel disease (IBD) $[1,2]$. Furthermore, as the population with IBD ages, it is not uncommon to encounter patients with a history of cancer, which poses therapeutic challenges, requiring multidisciplinary decisions. IBD treatment in the setting of prior cancer is complex and must consider several aspects such as the type of cancer and its potential for recurrence, as well as the severity of IBD and therapeutic alternatives. Most IBD drugs produce some level of immunosuppression, and therefore there is a concern that their use in patients with a prior history of cancer may increase the risk of new or recurrent cancer. There is evidence that patients with IBD treated with thiopurines exhibit an increased risk of lymphomas and nonmelanocytic skin cancers while those exposed to anti-TNF- $\alpha$ agents are at an increased risk of melanoma [3]. However, registry data and mostly observational retrospective studies across immune-mediated diseases have shown that the use of biologics in the setting of a prior cancer does not seem to increase the risk of incident or recurrent can-

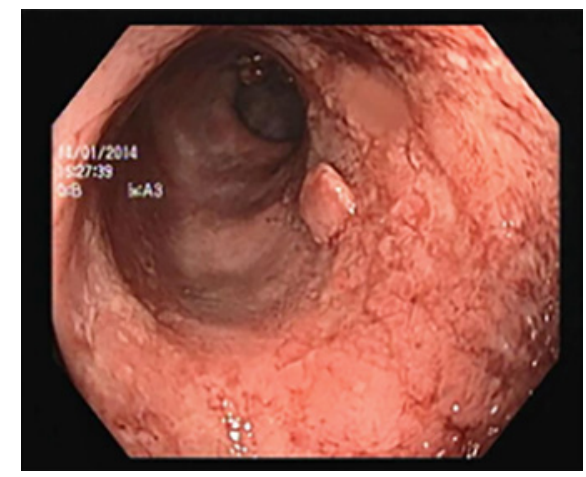

Fig. 1. Colonoscopy showing rectal involvement with mucosal friability, superficial ulcerations and pseudopolyps (Mayo 3) in 2013.

cer. In a retrospective cohort study, looking at IBD patients with a history of cancer, exposure to anti-TNF- $\alpha$ agents alone or in combination with thiopurines was not associated with a risk of new or recurrent cancer in the 5 -year follow-up period, even after adjusting for cancer recurrence risk [4]. The data available with newer biologics, such as vedolizumab (VDZ) and ustekinumab, are still limited, but overall, no major safety signal has yet emerged [5]. Herein we present the case of a 76-year-old man with a history of melanoma and steroid-dependent left-sided ulcerative colitis (UC), refractory to mesalamine and thiopurines, who went into clinical and endoscopic remission after starting VDZ and who was diagnosed with a multifocal colorectal cancer (CRC), shortly after. We discuss the challenges of treating IBD patients with a history of cancer and the potential role of VDZ in this setting.

\section{Case Report}

We present the case of a 76-year-old man, former smoker (40 pack-year units) with a medical history of arterial hypertension, psoriasis since the age of 23 treated with topical corticosteroids and calcitriol, and a prostatectomy due to benign prostate hyperplasia. He had no familial history of IBD or CRC. In 2009, he developed diarrhea and bloody stools and was diagnosed with left-sided UC. He was started on oral and topical mesalamine with good response. In 2011, a right scapula malignant melanoma stage Clark III was surgically removed. The surgery was curative, and the patient had no indication for systemic therapy, so he maintained the follow-up at a dermatology consultation. In 2013, he was referred to our IBD outpatient clinic. He complained of rectal bleeding, with around 6 bowel movements per day of liquid stools and fecal urgency, sometimes with incontinence. Laboratory workup showed hemoglobin of $13.4 \mathrm{~g} / \mathrm{dL}$, platelets of $320 \times 10^{9} / \mathrm{L}$ and C-reactive protein of 1.26 $\mathrm{mg} / \mathrm{dL}$. Colonoscopy revealed mucosal hyperemia, superficial ul- 
Fig. 2. Rectosigmoidoscopy revealing marked erythema, loss of vascular pattern and spontaneous bleeding (Mayo 3) under treatment with azathioprine in 2017.

Fig. 3. Rectosigmoidoscopy showing mucosal healing (Mayo 0) after vedolizumab introduction in 2018.
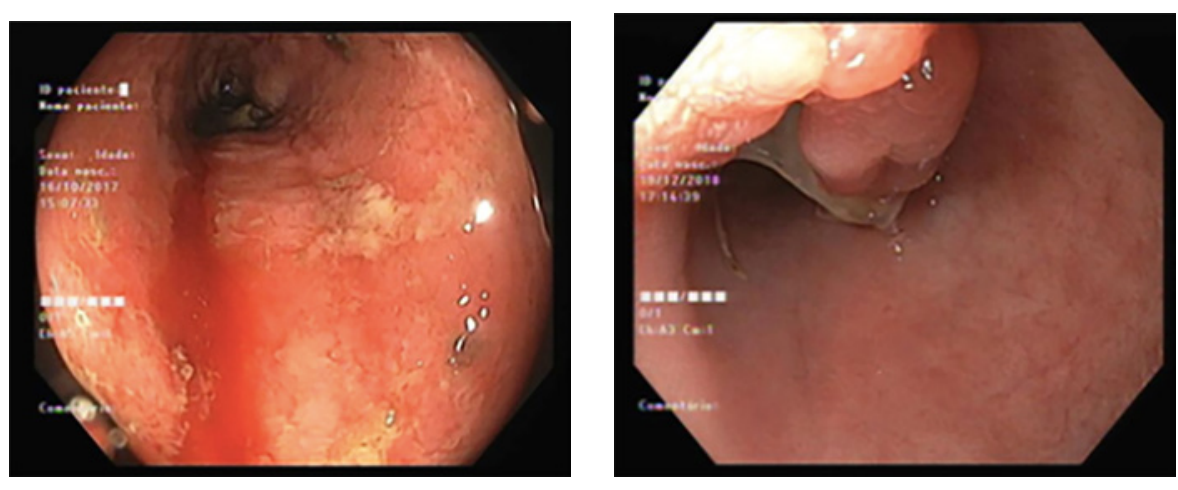

Fig. 4. Surveillance colonoscopy showing two areas of mucosal hyperemia with the use of light colonoscopy at $30 \mathrm{~cm} \mathrm{(a)} \mathrm{and} \mathrm{at}$ $25 \mathrm{~cm}$ (b) of the anal margin and another whitish appearance mucosal area visible with narrow band imaging (c), all of them with malignant cells on microscopic examination.
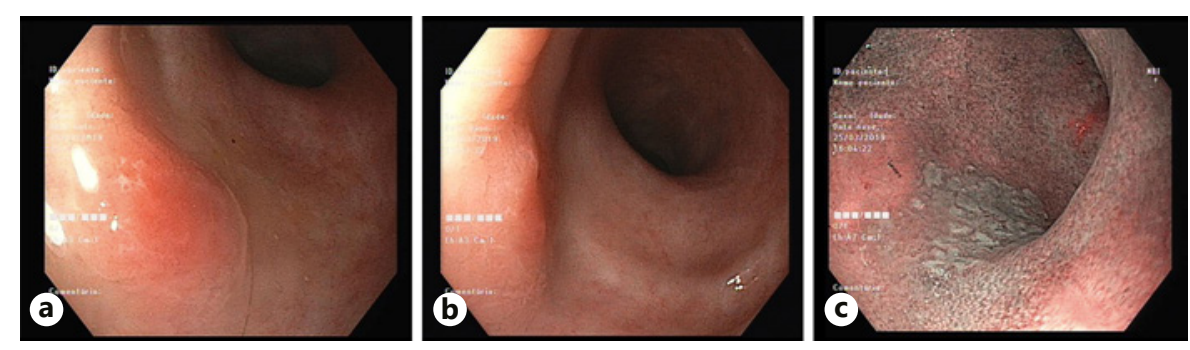

Fig. 5. Microscopic examination of biopsy specimen. a Poorly differentiated adenocarcinoma with inflammatory infiltrate and crypt distortion. Hematoxylin-eosin. $\times 40$. b Immunohistochemical study with staining of cancer cells. AE1/AE3. $\times 20$.
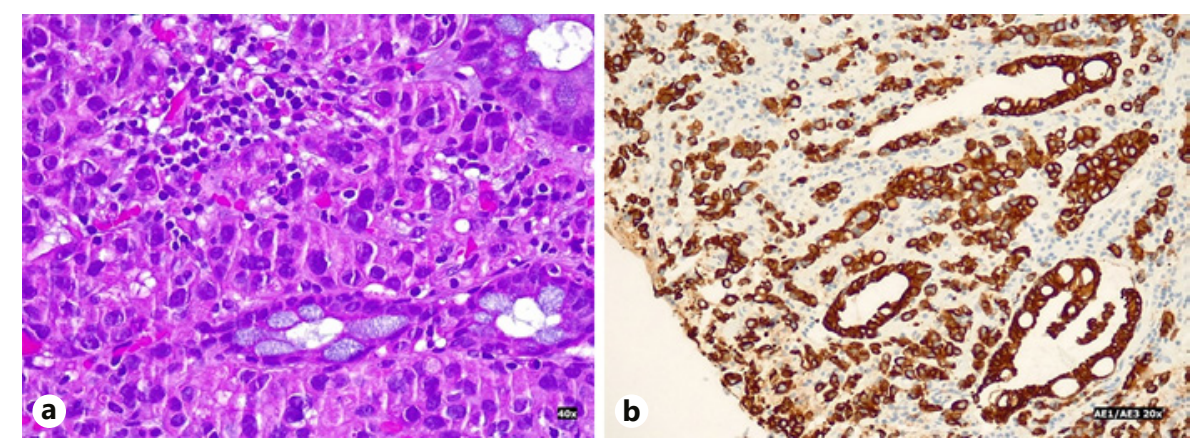

cerations and pseudopolyps in the rectum and sigmoid colon (Mayo 3) (Fig. 1). Colonic biopsies were consistent with active UC without dysplasia or cytomegalovirus infection. Oral and topical mesalamine were dose-optimized, with partial response only, requiring the addition of topical and oral steroids. The clinical course was marked by frequent relapses that required oral steroids. For this reason, a need for therapy escalation was discussed with the patient and with the dermato-oncologist. Given the recent history of melanoma, Dermatology considered that there was a relative contra-indication to start anti-TNF- $\alpha$ and the patient was started on azathioprine in 2016. Surgery was also discussed, but not considered an option by the patient. While on azathioprine, he had soft stool with a frequency of 3-4 bowel movements per day without blood. However, fecal urgency persisted and on endoscopy erythema, loss of vascular pattern and spontaneous bleeding were noticed (Fig. 2). In addition, azathioprine was stopped in 2017 due to a severe flare of genital herpes. The patient remained symptomatic, and endoscopy showed pseudopolyps, a tubular-looking co- lon with superficial ulcers in the sigmoid colon and rectum (Mayo 3). During this period, he was maintained on topical mesalamine. Considering the patient's advanced age and prior history of melanoma, he was started on VDZ in January 2018. Clinical remission with a stool frequency $<3 /$ day with no bleeding was achieved after 8 months of VDZ. The rectosigmoidoscopy showed endoscopic healing in the sigmoid colon and rectum, with a few colonic pseudopolyps (Fig. 3). Laboratory evaluation showed no anemia (hemoglobin $13.6 \mathrm{~g} / \mathrm{dL}$ ) or thrombocytosis, C-reactive protein of 1.07 $\mathrm{mg} / \mathrm{dL}$ and albumin of $4.4 \mathrm{~g} / \mathrm{dL}$. In February 2019, nine years after the initial diagnosis, the patient underwent his first surveillance colonoscopy. In the sigmoid colon, with the mucosa healed, it was possible to visualize two polyps of 5 and $10 \mathrm{~mm}$ (Paris $0-\mathrm{IIa}$ ) with adenomatous appearance in the descending and sigmoid colon. Pathology showed tubular and serrated adenomas with low-grade dysplasia on histological examination. Simultaneously, three different areas of flat mucosa in the rectum and sigmoid with an irregular crypt pattern were identified (Fig. 4). Biopsies of these 


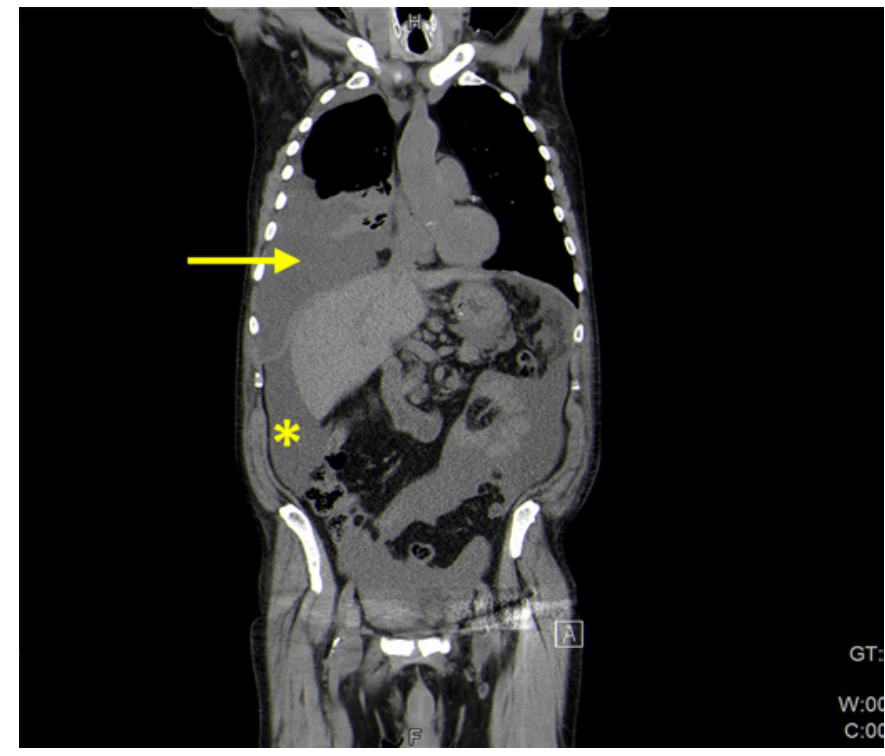

Fig. 6. Thoracic CT showing right pleural effusion (arrow) and voluminous ascites filling supra- and infracolic compartments $\left(^{*}\right)$.

areas revealed a synchronous poorly differentiated adenocarcinoma (Fig. 5). Carcinoembryonic antigen was $15.5 \mathrm{U} / \mathrm{mL}$. No loss of DNA mismatch repair proteins was detected (low probability of microsatellite instability), the KRAS, NRAS or BRAF mutations were negative, and the mutation for the human epidermal growth factor receptor 2 (HER2) was positive. Soon after the diagnosis of colorectal cancer he presented with abdominal distention and shortness of breath. Computed tomography of the chest-abdomen and pelvis showed a large-volume pleural effusion, ascites and a large epiploon densification (Fig. 6), consistent with secondary dissemination. Both ascites and pleural fluid cytology were positive for malignant cells. No liver or lung metastases were detected. After discussion in a multidisciplinary meeting, given the diagnosis of stage IVB colon adenocarcinoma with peritoneal and pleural involvement, dexamethasone and palliative systemic chemotherapy (cetuximab and FOLFIRI) were initiated. The patient's condition rapidly declined, and he died 3 months later. A notification of this case was reported to the INFARMED's national pharmacosurveillance program.

\section{Discussion}

The present report documents the clinical and endoscopic evolution of a patient with a left-sided UC refractory to mesalamine and thiopurines. The selection and escalation of treatment was particularly challenging given the patient's advanced age and history of skin cancer. We also highlight the rapid progression and the unusual metastasization pattern of an aggressive CRC developed 1 year after VDZ introduction.
Patients with UC have an increased lifetime incidence of CRC compared with the general population. In a metaanalysis, Eaden et al. [6] estimated that the cumulative probability of cancer is $2 \%$ at 10 years, $8 \%$ at 20 years and $18 \%$ at 30 years from symptom onset. There are some factors that predict the risk of CRC, namely the duration, extension and inflammatory activity of the disease [7]. Our patient had a UC with 9 years' duration with limited extension, albeit poorly controlled, which confers a low to intermediate risk of CRC. On the other hand, the persistent inflammatory activity (partial Mayo score $>3$ and endoscopic Mayo >2) until VDZ was started may have contributed to an increased risk of cancer. In this patient, therapy escalation and disease control were hindered by the history of melanoma. There is growing evidence linking anti-TNF- $\alpha$ therapy and an increased incidence of melanoma, due to changes in immune system checkpoints $[3,8]$. In a study using the British Rheumatology Biologic Registry, the risk of recurrent melanoma was higher in the anti-TNF- $\alpha$-exposed patient [9]. Altogether, these data, allied with the aggressiveness of melanoma, suggest caution in the use of anti-TNF- $\alpha$ in the context of this cancer and led our dermato-oncologist to suggest against this therapeutic class in our patient. On the other side, thiopurines have been linked to the nonmelanoma skin cancer and a higher risk of viral infections $[3,8]$. Despite discussing with the patient the possibility of surgery as an alternative therapeutic option, this was refused.

Surveillance colonoscopy has been endorsed to detect early dysplasia and re-evaluate disease extension and activity. The American Society of Gastrointestinal Endoscopy and the British Society of Gastroenterology guidelines advocate screening colonoscopy beginning 8-10 years from disease onset $[10,11]$. Although CRC is rarely encountered when disease duration is less than $8-10$ years, a substantial part of IBD-associated CRC may occur before colonic surveillance. Lutgens et al. [12] identified 149 patients with IBD-associated CRC and showed that about one fifth of the patients developed cancer before colonic surveillance should start. This fact suggests that besides extent and disease duration, some other risk factors such as age at UC onset and family history of CRC may decrease the time span between UC diagnosis and CRC occurrence. Our patient underwent surveillance colonoscopy, while in remission, about 9 years after symptom onset. Colonoscopy revealed three areas where very subtle mucosa alterations, characterized by changes in mucosal pattern, were more easily identified with narrow banding image. As he had never been in endoscopic remission before, it could had been difficult to identify 
these areas on colonoscopy due to mucosal chronic inflammation or absence of malignancy at this time. Besides, flat dysplasia is difficult to delineate and high-definition endoscopes are necessary to distinguish it from inflammation. There are controversial data regarding dysplasia and cancer detection during surveillance colonoscopy in UC $[13,14]$. Some studies demonstrated that surface pattern, as determined by narrow banding image magnifying colonoscopy, is useful for differentiation between UC-associated cancer/dysplasia and nonneoplastic lesions [14]. For this reason, the European Society of Gastrointestinal Endoscopy recommends the routine use of $0.1 \%$ methylene blue or $0.1-0.5 \%$ indigo carmine pancolonic chromoendoscopy with targeted biopsies and taking biopsies from flat mucosa surrounding neoplastic lesions or all suspicious lesions identified at neoplasia surveillance in long-standing colitis [15]. Flat dysplasia is rare but is more likely to be multifocal and often to progress to synchronous CRC compared with polypoid lesions as observed in our clinical case [10]. Besides the short time span between UC diagnosis and cancer development, with advanced stage of the CRC at diagnosis, what was also striking was the unusual spreading pattern of metastasis presented, since classic adenocarcinomas have a lower risk of peritoneal metastasis compared with mucinous and signet ring adenocarcinomas ( 20.1 vs. 48.2 and 51.2\%) [16]. HER2 overexpression is a relevant genetic alteration occurring in $5 \%$ of patients with metastatic CRC, being a negative predictor of response to cetuximab [17]. This may explain the rapid disease progression under treatment. However, the prognostic role and influence in overall survival of HER2 in CRC remains uncertain [17]. Likewise, the potential role of VDZ in the atypical presentation of this $\mathrm{CRC}$ is uncertain, but merits reflection. VDZ is a humanized monoclonal antibody targeting $\alpha_{4} \beta_{7}$-integrins approved for patients with moderate-to-severe IBD. Its safety profile has already been demonstrated in some clinical trials. Colombel et al. [18] gathered safety data from six clinical trials of VDZ where malignancy was reported in 18 of 2,830 patients exposed to VDZ. Six out of 18 of these patients had gastrointestinal malignancies, with 3 of them having CRC. These data are consistent with the expected risk observed in IBD patients [18]. In another systematic review and meta-analysis of randomized controlled trials from 49 studies reporting the incidence of malignancies, there was no association between VDZ exposure and cancer risk. However, this study is limited by short periods of exposure and follow-up [5]. A large retrospective multicenter cohort study concluded that the noninfectious serious events were low and were mostly related with the use of concomitant immunosuppressive therapy [19].

Although gut selectivity of VDZ may result in a more favorable safety profile in a high-risk population for cancer or infections, there is a theoretical concern, never confirmed, that by reducing the migration of activated leukocytes to the gastrointestinal tract, it may also reduce cancer immunosurveillance. A study with 68 patients treated with VDZ for more than 1 year found that ongoing VDZ responders with UC demonstrate mucosal healing after long-term follow-up. They also analyzed the colonic dysplasia and adenocarcinoma, identifying dysplasia in $10 \%$ of patients, but none of the other patients progressed to high-grade dysplasia or cancer [20]. In a retrospective observational study of 75 patients with IBD and primary sclerosing cholangitis, treated with VDZ for at least 30 weeks, 9 developed digestive cancer (7 CRC and 2 cholangiocarcinoma). Three cases of CRC were diagnosed between weeks 30 and 54 of therapy, and 4 cases were found between 1 and 3 years after the introduction of VDZ [21]. The development of digestive neoplasia might be attributable to the well-known increased risk of colorectal malignancy in this population, but the role of impaired immunosurveillance induced by VDZ should be evaluated. It can be postulated that the malignancy risk may be related to the impairment of the immunosurveillance of the gastrointestinal tract induced by anti-integrin antibodies [20]. More studies are necessary to address its effect on immunovigilance and the long-term malignancy risk. Finally, it is generally advised, solely based on the mechanisms of action, that this drug should probably be avoided in the setting of prior gastrointestinal cancers [22].

In summary, we present a clinical case of multifocal CRC detected 9 years after diagnosis, developing 1 year after VDZ therapy in a patient with poorly controlled leftsided UC. Strikingly, after achieving clinical and endoscopic remission, and 12 months after starting VDZ, the patient was diagnosed with CRC. The short time span between UC diagnosis and CRC detection in a patient with left-sided colitis, with multifocal poorly differentiated adenocarcinoma at diagnosis, and the atypical pattern of metastasization are unusual. Thus, we emphasize that comorbidities have important therapeutic implications in UC management and treatment should be individualized.

Acknowledgement

The authors do not have any acknowledgements to highlight. 
Statement of Ethics

The authors have no conflicts of ethics.

\section{Conflict of Interest Statement}

The authors have no conflicts of interest to declare.

\section{Funding Sources}

There were no funding sources relevant to this case report.

\section{Author Contributions}

Catarina Nascimento: acquisition and interpretation of clinical data for the case report; drafting the case report; corresponding author. Helena Oliveira: critically revising case report and final approval of the version to be published. Catarina Fidalgo: critically revising case report and final approval of the version to be published. Lídia Roque Ramos: critically revising case report and final approval of the version to be published. Luísa Glória: critically revising case report and final approval of the version to be published. Joana Torres: conception and design of the case; critically revising case report and final approval of the version to be published.

\section{References}

1 Pedersen N, Duricova D, Elkjaer M, Gamborg M, Munkholm P, Jess T. Risk of extra-intestinal cancer in inflammatory bowel disease: meta-analysis of population-based cohort studies [Internet]. Am J Gastroenterol. 2010 Jul;105(7):1480-7.

2 Beaugerie L, Itzkowitz SH. Cancers complicating inflammatory bowel disease. $\mathrm{N}$ Engl J Med. 2015 Apr;372(15):1441-52.

3 Beaugerie L, Kirchgesner J. Balancing Benefit vs Risk of Immunosuppressive Therapy for Individual Patients With Inflammatory Bowel Diseases [Internet]. Clin Gastroenterol Hepatol. 2019 Feb;17(3):370-9.

4 Axelrad J, Bernheim O, Colombel JF, Malerba S, Ananthakrishnan A, Yajnik V, et al.; New York Crohn's and Colitis Organization. Risk of New or Recurrent Cancer in Patients With Inflammatory Bowel Disease and Previous Cancer Exposed to Immunosuppressive and Anti-Tumor Necrosis Factor Agents. Clin Gastroenterol Hepatol. 2016 Jan;14(1):58-64.

5 Bonovas S, Fiorino G, Allocca M, Lytras T, Nikolopoulos GK, Peyrin-Biroulet L, et al. Biologic Therapies and Risk of Infection and Malignancy in Patients With Inflammatory Bowel Disease: A Systematic Review and Network Meta-analysis [Internet]. Clin Gastroenterol Hepatol. 2016 Oct;14(10):1385-1397. e10.

6 Eaden JA, Abrams KR, Mayberry JF. The risk of colorectal cancer in ulcerative colitis: a meta-analysis. Gut. $2001 \mathrm{Apr} ; 48(4): 526-35$.

7 Harbord M, Eliakim R, Bettenworth D, Karmiris K, Katsanos K, Kopylov U, et al.; European Crohn's and Colitis Organisation [ECCO]. Third European evidence-based consensus on diagnosis and management of ulcerative colitis. Part 2: current management. J Crohn's Colitis. 2017 Jul;11(7):769-84.

8 Long MD, Martin CF, Pipkin CA, Herfarth $\mathrm{HH}$, Sandler RS, Kappelman MD. Risk of melanoma and nonmelanoma skin cancer among patients with inflammatory bowel disease. Gastroenterology.2012 Aug;143(2):390399.e1.
9 Dixon WG, Watson KD, Lunt M, Mercer LK, Hyrich KL, Symmons DP; British Society For Rheumatology Biologics Register Control Centre Consortium; British Society for Rheumatology Biologics Register. Influence of anti-tumor necrosis factor therapy on cancer incidence in patients with rheumatoid arthritis who have had a prior malignancy: results from the British Society for Rheumatology Biologics Register. Arthritis Care Res (Hoboken). 2010 Jun;62(6):755-63.

10 Magro F, Gionchetti P, Eliakim R, Ardizzone S, Armuzzi A, Barreiro-de Acosta M, et al.; European Crohn's and Colitis Organisation [ECCO]. Third European evidence-based consensus on diagnosis and management of ulcerative colitis. Part 1: Definitions, diagnosis, extra-intestinal manifestations, pregnancy, cancer surveillance, surgery, and ileo-anal pouch disorders. J Crohn's Colitis. 2017 Jun;11(6):649-70.

11 Cairns SR, Scholefield JH, Steele RJ, Dunlop MG, Thomas HJ, Evans GD, et al.; British Society of Gastroenterology; Association of Coloproctology for Great Britain and Ireland. Guidelines for colorectal cancer screening and surveillance in moderate and high risk groups (update from 2002). Gut. 2010 May;59(5):666-89.

12 Lutgens MW, Vleggaar FP, Schipper ME, Stokkers PC, van der Woude CJ, Hommes DW, et al. High frequency of early colorectal cancer in inflammatory bowel disease. Gut. 2008 Sep;57(9):1246-51.

13 Watanabe K, Sogawa M, Yamagami H, Watanabe J, Ajioka Y, Arakawa T. Endoscopic differential diagnosis between ulcerative colitisassociated neoplasia and sporadic neoplasia in surveillance colonoscopy using narrow band imaging. Dig Endosc. 2011 May;23 Suppl 1:143-9.

14 Lv XH, Wang BL, Cao GW. Narrow Band Imaging for Surveillance in Inflammatory Bowel Disease: A Systematic Review and MetaAnalysis. J Clin Gastroenterol. 2019 Sep;53(8):607-15.
15 Bisschops R, East JE, Hassan C, Hazewinkel Y, Kamiński MF, Neumann $\mathrm{H}$, et al. Advanced imaging for detection and differentiation of colorectal neoplasia: European Society of Gastrointestinal Endoscopy (ESGE) Guideline - Update 2019. Endoscopy. 2019 Dec;51(12):1155-79.

16 Hugen N, van de Velde CJ, de Wilt JH, Nagtegaal ID. Metastatic pattern in colorectal cancer is strongly influenced by histological subtype. Ann Oncol. 2014 Mar;25(3):651-7.

17 Siena S, Sartore-Bianchi A, Marsoni S, Hurwitz HI, McCall SJ, Penault-Llorca F, et al. Targeting the human epidermal growth factor receptor 2 (HER2) oncogene in colorectal cancer. Ann Oncol. 2018 May;29(5):1108-19.

18 Colombel JF, Sands BE, Rutgeerts P, Sandborn W, Danese S, D'Haens G, et al. The safety of vedolizumab for ulcerative colitis and Crohn's disease. Gut. 2017 May;66(5):83951.

19 Meserve J, Aniwan S, Koliani-Pace JL, Shashi P, Weiss A, Faleck D, et al. Retrospective Analysis of Safety of Vedolizumab in Patients With Inflammatory Bowel Diseases [Internet]. Clin Gastroenterol Hepatol. 2019 Jul;17(8):1533-1540.e2.

20 Noman M, Ferrante M, Bisschops R, De Hertogh G, Van den Broeck K, Rans K, et al. Vedolizumab induces long-term mucosal healing in patients with Crohn's disease and ulcerative colitis. I Crohn's Colitis. 2017 Sep;11(9):1085-9.

21 Caron B, Peyrin-Biroulet L, Pariente B, Bouhnik Y, Seksik P, Bouguen G, et al. Vedolizumab Therapy is Ineffective for Primary Sclerosing Cholangitis in Patients With Inflammatory Bowel Disease: a GETAID Multicentre Cohort Study. J Crohn's Colitis. 2019 Sep;13(10):1239-47.

22 Sebastian S, Neilaj S. Practical guidance for the management of inflammatory bowel disease in patients with cancer. Which treatment? Therap Adv Gastroenterol. 2019 Jan;12:1756284818817293. 